\title{
Batalha dos papéis: Notas sobre as tensões entre procedimentos escritos e memória na regularização fundiária de terras de quilombos no Brasil ${ }^{1}$
}

\footnotetext{
Cristian J. Salaini ${ }^{2}$

Escola Superior de Propaganda e Marketing, São Paulo, Brasil ${ }^{3}$

salaini@gmail.com

Denise Fagundes Jardim ${ }^{4}$

Universidade Federal do Rio Grande do Sul, Porto Alegre, Brasil ${ }^{5}$

denisejardim@yahoo.com.br

Recibido: 3 de febrero de 2014

Aceptado: 26 de junio de 2014

Disponible en línea: 15 de marzo de 2015

O presente artigo realiza uma reflexão sobre os efeitos simbólicos e politicos de contextos periciais antropológicos em comunidades quilombolas, trazendo a tona elementos do reconhecimento social que ficam de fora da operação técnica e administrativa. Neste sentido, tem-se um artigo de caráter reflexivo sobre processos passados que envolvem antropólogos, comunidades quilombolas e agentes do Estado.

2 Doutor em Antropologia Social pela Universidade Federal do Rio Grande do Sul (2012).

3 É professor do curso de Relações Internacionais

4 Doutora em Antropologia pelo PPGAS do Museu Nacional/UFRJ

5 Professora associada do Departamento de Antropologia Participa do Programa de Pós-graduação em Antropologia Social da Universidade Federal do Rio Grande do Sul
} 


\title{
Batalha dos papéis: Notas sobre as tensões entre procedimentos escritos e memória na regularização fundiária de terras de quilombos no Brasil
}

\section{Resumo}

Esse artigo é uma reflexão sobre os processos de regularização fundiária ensejados pelo artigo 68 do Ato das Disposições Transitórias na Constituição Federal de 1988 no Brasil e seus desdobramentos nas rotinas administrativas estatais. Consideramos que se impõem novos elementos que devemos pensar sobre as politicas de reparação e de reconhecimento dos destinatários de tais dispositivos constitucionais. Evocamos a expressão da batalha dos papéis para referir às negociações travadas durante a realização dos procedimentos estatais cartoriais. Procurar-se-á revelar situações em que a luta por reconhecimento social desafia a ideia de que a demanda quilombola seja meramente territorial. Observados em seus diversos enfrentamentos, esses processos secretam uma vocação moral, conduzida pelos quilombolas, que transborda a lógica demandada pelo "mundo dos papéis" e nos permitem visualizar as tensões nas formas de dar materialidade, transladar da oralidade à escrita, conduzidas por noções de ciência e permeadas por lógicas cartoriais.

Palavras-chaves: etnicidade; territorialidade; quilombos; reconhecimento; perícia antropológica

\section{La batalla de los papeles: Notas sobre las tensiones entre procedimientos escritos y memoria en la regularización agraria de tierras de quilombos en Brasil}

\begin{abstract}
Resumen
Este artículo es una reflexión sobre los procesos de regularización agraria promulgados por el artículo 68 del Acto de las Disposiciones Transitorias en la Constitución Federal de 1988 en Brasil y su despliegue en las rutinas administrativas estatales. Consideramos que se imponen nuevos elementos que debemos pensar sobre las políticas de reparación y de reconocimiento de los destinatarios de esos dispositivos constitucionales. Usamos la expresión de la batalla de los papeles para referirnos a las negociaciones entrabadas durante la realización de los procedimientos estatales notariales. Se procurará mostrar las situaciones en las que la lucha por el reconocimiento social desafia la idea de que la demanda de los esclavos cimarrones sea meramente territorial. Observados en sus diversos enfrentamientos, esos procesos ocultan una vocación moral, dirigida por los cimarrones, que desborda la lógica demanda por el "mundo de los papeles" y nos permite visualizar las tensiones en las formas de dar materialidad, trasladadas desde la oralidad hacia la escritura, conducidas por nociones de ciencia y permeadas por lógicas notariales.
\end{abstract}

Palabras clave: etnicidad; territorialidad; quilombos; reconocimiento; experiencia antropológica

\section{The battle of papers: Notes on the Tensions between Written Procedures and Memory in the Agrarian Regularization of Quilombo Lands in Brazil}

\begin{abstract}
This article is a reflection on the processes of land regularization enacted by the section 68 of the Temporary Constitutional Provisions Act of 1988 in Brazil and its deployment in the State administrative routines. We believe that new elements have been imposed and we should consider them when thinking about reparation policies and recognition of the recipients of these constitutional provisions. We use the expression "the battle of papers" to refer to the negotiations obstructed by the State notarial procedures. Efforts will be made to show the situations in which the struggle for social recognition challenges the idea in which it is conceived that the runaway slaves demand is merely territorial. Observed in their various confrontations, these processes conceal a moral vocation, led by the runaway slaves, that overflows the logical demand for the "World of papers" and allows us to visualize the tensions on the ways of materializing, moved from orality to writing, conducted by notions of science and permeated by notary logic. Keywords: ethnicity; territoriality; quilombos; recognition; anthropological experience
\end{abstract}




\section{Introdução}

Este artigo é uma reflexão sobre os processos de regularização fundiária ensejados pelo artigo 68 do Ato das Disposições Transitórias na Constituição Federal de 1988 no Brasil e seus desdobramentos nas rotinas administrativas estatais. Para esta ação estatal de caráter reparatório, desde 1998, o trabalho antropológico vem sendo solicitado pelo Ministério Público Federal como parte da perícia em processos judiciais movidos por comunidades negras através de convênios entre o poder público estadual, federal e as universidades públicas para a realização de laudos antropológicos.

A partir de 2003, o artigo constitucional passa a ser regido por decreto presidencial n. 4887 de 2003, definindo atribuições de órgão da administração para o processo demarcatório. A Fundação Cultural Palmares, órgão ligado ao Ministério da Cultura, passa a emitir certidões de reconhecimento de comunidades, um tema que vinha sendo debatido desde 2000. Aos antropólogos, cabe participar não mais como peritos chamados pelo Ministério Público, mas diretamente envolvidos nas rotinas administrativas da produção do Relatório Técnico de Demarcação e Identificação (RTDI) junto ao Instituto Nacional de Reforma Agrária (INCRA), órgão federal então responsável pela emissão dos títulos de propriedade para as associações comunitárias que representam as comunidades quilombolas. Segundo dados da Fundação Cultural Palmares, existem no país 2040 comunidades certificadas, 1229 processos abertos para titulação de terras no INCRA e 207 comunidades tituladas, beneficiando 12.906 famílias $^{6}$.

Examinamos aspectos que devem ser compreendidos como situações comuns ao transcorrer dos pleitos de terras quilombolas nas rotinas administrativas e que evidenciam um dificil diálogo entre comunidades negras e as instituições administrativas e estatais ${ }^{7}$. Apresentamos algumas das tensões entre essas lógicas cartoriais e as noções nativas manejadas durante a realização do relatório das

\footnotetext{
6 Ver Fundação Cultural Palmares em http://www.palmares.gov.br/2013/05/lancado-relatoriode-gestao-2012-do-programa-brasil-quilombola/

7 Sobre o chamado 'racismo institucional' ver Lopez (2013) e Jardim (2013).
} 
comunidades pleiteantes. Na primeira parte do artigo, destacamos a relação histórica das comunidades com o Estado cartorial, levantadas nos diferentes relatórios técnicos empreendidos. Evidenciamos os processos de invisibilização dessas comunidades negras como parte da experiência vivida pelas comunidades com os expedientes cartoriais pretéritos. $\mathrm{Na}$ segunda parte, através de exemplos trazidos da experiência etnográfica, indagamos sobre o modo como novas 'batalhas dos papéis' interpelam os quilombolas durante os pleitos de regularização fundiária na atualidade.

Buscamos evidenciar algumas das lógicas que postergam ou ensejam a titulação. Com isso, não pretendemos reduzir tais enfrentamentos históricos vivenciados pelas comunidades pleiteantes, em sua singularidade e complexidade, aos momentos atuais da luta pela titulação de territórios tradicionais. Tampouco seria possível traduzir suas lutas históricas através do que é apreendido apenas enfocando o diálogo entre comunidades e as instituições estatais que recepcionam os pleitos de titulação territorial. Entendemos, contudo, que, para compreender o fenômeno da etnicidade e seus desdobramentos, é necessário examinar os caminhos trilhados pelos pleitos territoriais perante as politicas administrativas estatais e observar as dificuldades da implementação de políticas de reconhecimento e reparação histórica para as comunidades negras no Brasil.

Para tanto, partimos de duas noções fundamentais. A primeira é a compreensão da etnicidade como um fenômeno de comunização que fortalece laços de lealdades, revitaliza um repertório comum e que, de outra parte, fornece um idioma de inclusão e fronteiras pertinentes à coletividade para delimitar pessoas que 'fazem parte' de sua vida coletiva. O debate sobre os 'interesses' que tal fenômeno mobiliza, muitas vezes, torna a perspectiva instrumental dos processos de comunização como um dos seus eixos explicativos fundamentais. Oliveira Filho (1999) refere aos pressupostos de perspectivas instrumentalistas e primordialistas sobre a etnicidade. Tal debate tem se desdobrado no contexto da elaboração de relatórios como uma suspeição sobre o interesse por parte das comunidades em ingressar em esferas públicas com a finalidade de recuperar territórios históricos. A suspeição de que tais comunidades se mobilizam com finalidades 
pragmáticas negligencia todo um debate que se trava na vida comunitária sobre sua própria capacidade de enfrentamento e autossustentação durante a conflagração de um pleito territorial e repercute, inclusive, nas formas específicas de enfrentar e equacionar as relações sociais de subordinação que estabelecem com vizinhos e invasores de seus territórios.

A noção de territorialidade também tem sido fundamental para apreender o fluxo da vida comunitária no âmbito dos relatórios técnicos ${ }^{8}$. Tal noção comportaria aspectos existenciais e simbólicos relacionados aos modos de gerir a vida em comum nas localidades. Dessa maneira, transbordaria a concepção de unidade territorial, perspectiva colonial que buscava relacionar uma etnia a um exclusivo território fisico, aprimorando formas de controle e governo de populações nativas, e que estava invariavelmente amparada por saberes científicos que definiam 'unidades territoriais' a partir de dimensões espaciais e cartográficas. Tais noções cartoriais exigem delimitação e englobamento, definindo um perímetro, critérios e noções de 'dentro' e 'fora' a serem estabilizadas em mapas. Cartograficamente, o recurso impõe definir fronteiras ao transcurso da vida social nas localidades e se apresenta como princípio objetivo da realidade social. Romper com a noção de território, para fazer emergir a territorialidade, implica abandonar lógicas objetivantes que reduzem o mapa territorial a recortes de perímetros.

Esta reflexão é resultado de um longo período de interlocução com os antropólogos que realizaram relatórios técnicos no sul e no nordeste do Brasil, especialmente os envolvidos nas equipes constituídas pelo Núcleo de Antropologia e Cidadania no PPGAS/UFRGS. Pretende indagar sobre como a antropologia tem feito parte da realização dos procedimentos e políticas estatais de reparação territorial e, ao mesmo tempo, deste ponto de observação e imersão, refletir criticamente sobre os novos enfrentamentos das comunidades quilombolas quando tramitam seus pleitos em esferas institucionais.

\footnotetext{
8 A este respeito ver Leite (1995). O debate sobre a inserção de antropólogos reverbera na produção de documentos no âmbito da Associação brasileira de Antropologia e reflexões que se estendem sobre o papel dos antropólogos nas arenas de direitos sociais, como refere Oliveira Filho (2004), O`Dwyer (2010) e Chagas (2010).
} 
Procurar-se-á revelar algumas das situações em que as lutas, aqui consideradas como lutas por reconhecimento social, extrapolam a ideia de que a demanda quilombola seja meramente territorial. Observações em diversos enfrentamentos nesses processos secretam uma vocação moral, conduzida pelos quilombolas, que transbordam a lógica demandada pelo 'mundo dos papéis' e nos permitem visualizar as tensões entre oralidade e escrita bem como noções de ciência permeadas por lógicas cartoriais. Nesse sentido, adotamos como ponto de partida algumas das proposições de Honneth (2003) em que o conflito social é, antes de uma demanda por regulação, uma gramática moral dos conflitos sociais. Orientados por essa proposta, retomamos 'a luta por reconhecimento' como algo que tem escalas diversas que não se esgotam no momento normativo de uma luta social, ou de seus ganhos pragmáticos. A noção de intersubjetividade nos processos identitários nos permite colocar em evidência -de modo etnográfico- suas tensões constituintes. Elas estão distantes da constante suspeição a que são submetidos os processos identitários. A noção de intersubjetividade nos processos identitários evidencia o quanto estão distantes de uma esfera meramente restrita a um interesse individual e, sim, relacionados ao respeito e à estima social de uma pessoa ou de um grupo, de suas maneiras de comunicação e relações intersubjetivas, e ao próprio reconhecimento que lhe seja correspondente. Em suas palavras;

[...] mesmo aquilo que, na qualidade de interesse coletivo, vem a guiar a ação num conflito não precisa representar nada de último e originário, senão que já pode ter se constituído previamente num horizonte de experiências morais, em que estão inseridas pretensões normativas de reconhecimento e respeito. (Honneth: 2003, p. 262)

Não se argumenta sobre uma relação de causalidade entre estes diferentes niveis do reconhecimento, como se fosse necessário que os grupos percorressem certas 'etapas'. No entanto, a apreensão de determinadas escalas do reconhecimento auxilia no entendimento da complexa teia que é constituída de possibilidades de reconhecimento de ordem moral, produzido também no âmbito das microrrelações. Estas, contudo, podem ou não produzir um encadeamento de fatos da vida social que façam com que experiências isoladas procurem respaldo num enquadramento ético de maior superficie, por exemplo, o 
Estado (Honneth, 2003). Contudo, o sentimento de desrespeito, conforme demonstra Honneth, apresenta-se enquanto um elemento potencial para que essa percepção individualizada se incorpore em um ordenamento comunal e, portanto, nos permite compreender aspectos dessa autonomia derivada de uma relação intersubjetiva. É necessária a construção de uma ponte semântica entre o individual e o coletivo:

Por fim, a alternativa entre finalidades pessoais e impessoais tampouco é inteiramente pertinente em relação a uma luta assim entendida, visto que em principio esta só pode ser determinada por idéias e exigências gerais, em que os diversos atores vêem positivamente superadas suas experiências individuais de desrespeito; entre as finalidades impessoais de um movimento social e as experiências privadas que seus membros têm da lesão, deve haver uma ponte semântica que pelo menos seja tão resistente que permita a constituição de uma identidade coletiva. (Honneth, 2003, pp. 257-258)

\section{Práticas cartoriais e as politicas de reparação e reconhecimento}

Desde julho de 2001, através de convênio firmado com a União Federal (recepcionado pelo Ministério Público Federal), a Fundação Palmares (Ministério da Cultura) e o Estado do Rio Grande do Sul, a comunidade quilombola de Morro Alto se torna objeto de trabalho de identificação e delimitação de seu território a fim de dar materialidade aos direitos constitucionais consignados na Constituição de 1988. É o momento em que uma equipe de pesquisadores do Núcleo de Antropologia e Cidadania (NACi) inicia seu envolvimento com a elaboração de laudos, coordenados diretamente por professores universitários. Anteriormente, tais pleitos eram movidos de forma coletiva em outros formatos, seja como uma tentativa de regularização de posse pela via jurídica individual do processo de requerimento de posse individual por usucapião, seja pela regularização através de movimentações coletivas quando os sujeitos eram atingidos por barragens ou projetos de impacto ambiental ${ }^{9}$.

\footnotetext{
9 A esse respeito, ver Carvalho (1995), O`Dwyer (2010) e Almeida (2011), entre outros.
} 
A aproximação com diferentes processos demarcatórios acabava revelando aos pesquisadores as dificuldades de comunidades negras rurais e urbanas, ao longo dos séculos XIX e XX, em se fazerem visíveis nos desenhos cartoriais disponiveis, relativos à propriedade privada individual e através das instâncias de registro cartorial localmente disponíveis. Além disso, para acessar políticas públicas relativas a saneamento básico, educação e políticas de renda mínima, tal invisibilização era reiterada ao exigir documentos de nascimento, óbito e outros registros emitidos por cartórios que comprovavam sua existência e vida individual e coletiva na localidade ${ }^{10}$.

Estar visível, fazer-se visivel para as instituições públicas, consistia em um dos dilemas fundamentais que, por certo, extrapolam os sentidos jurídicos e administrativos, mas estavam em jogo e dinamizavam diversos atores, como famílias, comunidades constituídas pela convivência com os vizinhos e aparentados, bem como movimentos sociais organizados e aqueles que foram se organizando na própria experiência desses sujeitos com os procedimentos das políticas demarcatórias, frente a seus entraves e beneficios quanto ao acesso a saneamento básico, moradias, fornecimento de energia, inserção em programas de renda mínima, entre outros, tão importantes quanto o enfrentamento a novos episódios de esbulho territorial com que algumas comunidades se defrontam durante o procedimento demarcatório.

O primeiro decreto presidencial n. 3912 de $2001^{11}$ sustentava a necessidade de comprovação de conexões históricas entre as comunidades e a experiência escravocrata. A precariedade da materialidade de comprovações históricas positivas de antemão desqualificava os sujeitos pleiteantes como usurpadores da história de seus antepassados. O próprio decreto acabara definindo os sentidos de reparação histórica e atrelando a ideia de comprovação histórica. ${ }^{12}$

\footnotetext{
10 Tal situação é registrada no trabalho de Lima (2011). O Ministério Público Federal tivera que interceder em situações pontuais, durante o andamento do processo demarcatório federal, para cobrar e dirimir a resistência de órgãos públicos locais, executores de políticas públicas de prefeituras, em atender as comunidades quilombolas quanto ao saneamento básico. As alegações institucionais eram que ocupações irregulares e não teriam como acessar serviços públicos.

11 O Decreto 3912/01 afirmava que somente poderia ser reconhecida a propriedade sobre terras que, entre outras coisas, eram ocupadas por quilombos em 1888 e estavam ocupadas por remanescentes das comunidades dos quilombos em 05 de outubro de 1988.

12 A este respeito ver Leite (1995), Almeida (2011) e Arruti (2006).
} 
O decreto 4887 de 2003, que substitui o primeiro decreto, retira esse argumento de conexão histórica e define o INCRA como órgão responsável pelo procedimento administrativo da titulação. Para o Ministério Público Federal, os casos até então tomados como demandas contra violações do Estado se transladam a uma arena que, teoricamente, deveria acolher pleitos como procedimentos ordinários. Se tomarmos a recente expansão de recursos institucionais disponíveis na legislação, esse é um momento em que há uma expressão pública do valor conferido à promoção de igualdade de acesso aos direitos sociais e das preocupações em promover politicas de reparação e o reconhecimento social. No entanto, o reconhecimento direto dos protagonistas, de suas narrativas históricas e de sua visibilidade como "sujeitos de direitos" permanece um dilema e um enfrentamento diário para as comunidades quilombolas. Portanto, queremos chamar a atenção para o fato de que não se tratava pura e simplesmente de um momento de solucionar a operacionalização de novas leis, mas de examinar a receptividade (maior ou menor) de alteridades, da própria presença histórica e de narrativas sobre os modos de gerir a vida em comum nas localidades, nos procedimentos demarcatórios. Nas experiências de perícia, percebe-se que os elementos simbólicos que dão os contornos e tornam compreensivel a vida em comunidade acabam tornando-se o principal problema de enunciação e de dificuldade de comunicação com as lógicas estatais pautadas pelas comprovações materiais da vida comunitária.

A cooperação que realizamos entre antropólogos e historiadores tem demonstrado que a vulnerabilidade e os acessos desiguais a que são submetidas as coletividades afrodescendentes também são reveladores de uma experiência de resistência política e social que atravessa séculos. Estudos como Carvalho e Weimer (2003) sobre o quilombo da Família Silva em área urbana de Porto Alegre, por exemplo, revelavam as narrativas de esbulhos ocasionadas pela precariedade de acesso a registros cartoriais através de usucapião. O trabalho de campo acessava tanto a história de ocupação da localidade, em um percurso histórico com episódios de constantes despejos até a fixação final de residência, como as incursões e entraves jurídicos que vulnerabilizavam a comunidade negra no acesso a documentos da terra em que viviam. O fato dos Silva terem iniciado muitas vezes o processo de usucapião demonstrava 
a sua desvantagem no acesso e manejo dos recursos jurídicos e a extrema dependência que tiveram, ao longo de suas trajetórias, de intermediadores (nem sempre idôneos) advindos de suas relações com pessoas letradas e advogados.

No quilombo de Mormaça, o relatório técnico (Jardim et alli: 2007a) levantava não somente a vida em comum quilombola e a história da ocupação das terras relacionada à descendência de membros da família que formavam o plantel de escravos de senhores de terra. Os registros cartoriais, em especial os mapas levantados pela historiadora da equipe, recuperavam um primeiro procedimento de registro da terra, em função da operacionalização da Lei de Terras (1850) em uma de suas etapas, a do processo de identificação de terras devolutas (da União). Esta era uma ação que cartorialmente permitia nominar a presença dos ancestrais dos pleiteantes. Tal registro fora absolutamente desconsiderado posteriormente no processo de colonização oficial de terras públicas. O avanço sobre o mato (dos colonos oficiais em direção aos moradores ex-escravos) demonstrava um processo de invisibilização dos descendentes e encontrava respaldo na negligência oficial ao desconsiderar o registro cartorial anterior, em que os sujeitos eram situados nominalmente em parcelas conferidas a eles pelos senhores de escravos da região, como estratégia senhorial de imobilizar as terras e não disponibilizá-la para a União. Ora, essa sobreposição de atos cartoriais, reitera a ideia de vazio territorial presente na argumentação contrária ao pleito na atualidade, e transformava percursos anteriores à presença de novos colonos cartorialmente inexistentes, nos oferecendo um bom exemplo do processo de invisibilização das comunidades negras no sul do Brasi1 ${ }^{13}$.

No caso da comunidade do Areal da Baronesa, situada em um bairro da cidade de Porto Alegre, os relatos sobre o território revelavam as intensas conexões entre as famílias ali residentes e a necessidade

\footnotetext{
${ }^{13}$ Jardim et alli (2007a), o dialogo na equipe permitiu entender que os marcos geográficos manejados pela comunidade se reportavam a uma base cartorial que a historiadora tinha levantado em arquivos e que não mais era manejada pela cartografia disponivel em órgãos estatais. Em uma das reuniões, as geógrafas da equipe tiveram seu mapa corrigido pelo quilombola que afirmava que determinado prolongamento de rio seria, na verdade, um rio que foi transposto pelo cultivo agrícola e que tinha outro nome. Em outras palavras, a experiência com o espaço por si só, o conhecimento de suas transformações, já demonstravam a enorme familiaridade e relação histórica com o mapa e, fundamentalmente, com o território.
} 
de negociar sua permanência com o quartel da brigada militar que se instalara ao seu lado. Formas de reciprocidade e vizinhança se externavam e, ao mesmo tempo, mostravam o delicado cálculo da comunidade, ao longo de sua existência, por ceder espaços e coexistir com os equipamentos e espaço físico que a corporação ocupara ${ }^{14}$. Era diretamente 'contra' relações históricas delicadas e negociadas constantemente que a conflagração de um pleito de regularização era calculado como viável ou indesejável por parte das lideranças quilombolas.

Como sugere Sally Falk Moore (1978), é importante observar como o poder da lei costuma ser altamente circunscrito em qualquer contexto social. A relação entre leis e práticas é considerada como uma mutualidade constitutiva. O foco, portanto, do trabalho antropológico não seria mostrar os "usos das leis" remetendo a uma ideia de deturpação de seus princípios quando observados na prática. Pelo contrário, indagaria sobre as "condições sociais de possibilidade", como refere Claudia Fonseca (2004). Ou seja, como se dá a emergência de discursos legais, que não se esgotam na lei e que, de outra parte, pretendem desvendar os dispositivos que geram a desigualdade de acessos à justiça.

Como afirma Honneth (2003), há um enorme desafio para promover o sentimento de igualdade para sujeitos que foram destituídos de um reconhecimento de suas formas narrativas. Aqui destacamos outro aspecto debatido por Honneth, que aponta para a desqualificação de sua objetividade desautorizando sua capacidade comunicativa. No que tange às políticas de demarcação, percebemos ser esse um desafio ainda maior de promover uma escuta institucional aos pleitos e narrativas quilombolas, e entendê-los como existentes em sua plenitude, recepcionando-os na vida administrativa. Assim, é importante apontar para a importância de refletir sobre os desafios das politicas de reparação adotando um passo necessário de reconhecimento dos interlocutores como sujeitos autorizados a expressarem seus pontos de vista. Uma das dificuldades reside exatamente no reconhecimento de que estamos diante de pessoas que foram moralmente degradadas. Embora, a nosso ver, sejam capazes de elaborações de sua experiência vivida, as lógicas institucionais correm o risco de sistematicamente

\footnotetext{
${ }_{14}$ Ver Jardim et alli (2007b).
} 
desautorizar e não recepcionar suas narrativas e formas de entendimento do mundo por considerá-las "menos objetivas"15.

A antropóloga Rita Segato (2006) nos chama a atenção para o problema fundamental que decorre deste tipo de racismo, que desqualifica uma visão de mundo e seus instrumentos de compreensão do mundo social, classificando-os como ilegiveis. Indaga sobre o que sinalizamos a pessoas e segmentos quando retiramos de seu horizonte a possibilidade de manejar os recursos legais e instrumento administrativos que encaminham para uma reparação pública, administrativa ou jurídica. Ou seja, imediatamente subtraímos de seu horizonte a possibilidade de vir a ser reconhecido como um interlocutor visivel ao Estado nação e aos sujeitos com quem tem se relacionado na vida nas localidades. Esse dano subjetivo, diria Honneth (2003), a nosso ver, significa a potencial subtração de uma modalidade narrativa do campo de possiveis narrativas alçadas como registro fidedigno e histórico e, assim, desconsideradas como verídicas nas lógicas jurídico-administrativas.

O caminho administrativo está, atualmente, permeado de atos judicializantes, mas não uma 'judicialização' em busca de direitos e, sim, uma instrumentalização da ciência jurídica na protelação dos direitos constitucionais de comunidades quilombolas que merece nossa atenção e exame. A morosidade do andamento das etapas deve ser considerada como parte de um problema mais complexo sobre a conjunção das pressões políticas e da recursividade jurídica em bloquear a efetividade do procedimento, em que jogam elementos diversos como a rigidez de lógicas administrativas em recepcionar situações singulares, fazendo com que situações particulares sejam tomadas como excepcionalidades que perturbam a regra. As alterações das formas de custeio e contingenciamento de recursos para financiar procedimentos administrativos, entre outros, também fazem parte dos descaminhos da política de titulação.

\footnotetext{
${ }^{15}$ Honneth (2003) examina os primeiros enfrentamentos para o emprego e as totalizações efetuadas tão rapidamente, sobre a palavra "dignidade" para as políticas de reparação. Segundo ele: "Ora, é visivel que tudo o que é designado na língua corrente como "desrespeito" ou "ofensa" pode abranger graus diversos de profundidade na lesão psíquica de um sujeito”. (Honneth: 2003, p. 214)
} 
Em 2010, mudou-se a definição das formas de recrutamento de peritos que realizariam os RTIDs. Nesse momento, aos convênios com universidades que vinham produzindo relatórios em um compasso lento, criou-se a alternativa de um sistema de cotação de contratações de especialistas por menor preço de mercado, com o qual se acreditava impulsionar e dar maior agilidade e volume os relatórios técnicos.

\section{A 'objetividade' nas narrativas e relatórios técnicos}

Destacamos dois aspectos dessa objetivação pretendida pelo universo jurídico/administrativo. O primeiro diz respeito ao modo como as instruções normativas tendem a recepcionar as narrativas quilombolas e os fatos relativos à sua memória. Um segundo aspecto diz respeito às formas de dar materialidade cartográfica ao mapa que orientará o processo demarcatório. Ora, se as políticas de reparação visam considerar outras experiências sociais com territórios e com o mundo social, a escuta e a tradução de tais narrativas se encontra, uma vez mais, em tensão com lógicas jurídico-administrativas que, em muitos casos, precipitaram as situações de desvantagem histórica das comunidades quilombolas.

\section{A elaboração de relatórios sob nova instrução normativa e as narrativas quilombolas}

Os procedimentos administrativos introduziam exigências estranhas à disciplina antropológica, e revelavam uma valorização de parâmetros tidos e vistos como mais "objetivos", mas que procuravam gerar uma fixidez a formas complexas que perfazem as experiências sociais dos diversos grupos estudados, além de buscar 'aspectos comuns' concebidos como parte do cumprimento de um rigor em objetivar realidades sociais. Se esse rigor parece inatingivel, no que tange às experiências sociais e às formas consagradas de análise antropológica, onde "as regras nem sempre se prestam a ser formalizadas nem ditas, como no conjunto das ciências humanas ancoradas no método qualitativo" (O’Dwyer, 2010, p. 58), as lógicas administrativas acabavam 
buscando conceitos científicos para balizar suas práticas de objetivação de alteridades.

A preocupação com a constituição de uma 'área efetivamente ocupada' se torna uma das metas administrativas, instaurando, nos próprios relatórios, a necessidade de estabelecer nuances e de discriminar a área historicamente ocupada, a área efetivamente ocupada e a área pleiteada para demarcação. Tais definições se baseavam no receio sobre possiveis impactos negativos que uma área definida através do contato com os próprios agentes do pleito - quilombolas - poderia gerar (na definição de áreas indígenas e de trabalhadores sem-terra, por exemplo), e no trabalho de execução por parte da administração, tal como "levantamento de matrículas" de propriedade, situações em que as terras quilombolas poderiam estar exatamente em territórios ocupados por setores do poder público. Assim, esta 'preocupação' em objetivar territórios nos processos administrativos vai além de uma 'atitude interessada' enquanto desencadeadora do pleito territorial por parte de comunidades quilombolas, ela nos demonstra a quantidade de negociações que entra em curso no momento do processo demarcatório ${ }^{16}$.

Em 20 de outubro de 2009 a IN $49^{17}$ é substituída pela IN 57. O artigo 10 da IN traz, entre outras coisas, a fundamentação do RTID (Relatório Técnico de Identificação e Delimitação) baseado em 'elementos objetivos' no que diz respeito às informações antropológicas e etnográficas. Cabe notar que o movimento quilombola interpreta as mudanças apresentadas na IN 57 como um retrocesso às demandas política deste setor da sociedade brasileira. A construção de tal IN é entendida como o resultado de pressões de proprietários de terras, órgãos militares e de setores do parlamento federal, como aquela produzida, ainda em 2004, pelo DEM (Democratas e antigo PFL) com a intenção de impetrar ação de inconstitucionalidade ao Decreto 4.887/03.

\footnotetext{
${ }^{16}$ Estabelecer como centro do debate as dinâmicas culturais sobre o território, ao invés de uma "natureza humana" interessada, pode evitar "um fim trágico ao se imaginar que a variedade etnográfica não existe, ou decretar, simplesmente, que ela venha a desaparecer com a definição externa, e não de dentro, do que são as terras 'efetivamente ocupadas"' (O'Dwyer, 2010, p.60).

17 As discussões que envolveram a construção da Instrução Normativa 49 (a qual substituiu a IN 20 em 29 de Setembro de 2008) apresentavam como argumentação fundamental a possibilidade de se objetivar critérios para a verificação da identidade quilombola. O debate sobre sua alteração apresentava a ideia de adotar um rigor maior sobre o formato dos relatórios.
} 
Por não se 'enquadrarem' nas classificações jurídicas hegemônicas e por servirem de arena de disputas entre sujeitos com recursos desiguais, paradoxalmente, as políticas de reparação e reconhecimento parecem sofrer do mesmo problema a que vieram solucionar. Na esfera administrativa, as lógicas persistentes que não recepcionam a diferença e que buscam enquadrá-las como exceções ou 'distúrbios da ordem' recolocam em cena saberes e compreensões que desqualificam previamente pleitos e sujeitos. Portanto, os mecanismos protelatórios são bastante complexos, eles nos permitem conhecer as conexões entre os debates políticos e sua influência no setor administrativo, transfigurando instruções normativas, exigindo maior 'poder de precisão' em classificar e nomear os beneficiários das politicas reparatórias. Dessa forma, é interessante perceber o quanto uma política de inclusão de protagonistas é disputada e se converte em um mecanismo de denegação de direitos, pelo menos assim é experimentada pelos pleiteantes. Mas, de todo modo, não é possivel delegar as razões da postergação a uma lei imperfeita ou a um decreto impreciso, se não recuperar as dificuldades de efetivamente 'reconhecer' as desvantagens dos sujeitos em manejar códigos dominantes (jurídicos, científicos e administrativos).

Durante dois anos, de meados de 2009 até o final de 2011, sob os novos parâmetros da Instrução Normativa número 57, o desafio foi o de participar da construção de relatórios antropológicos no estado do Sergipe ${ }^{18 .}$ A busca por 'elementos objetivos', apresentada na IN trazia dificuldades ao trabalho antropológico e etnográfico. Um "clima de busca por dados objetivos" parecia tomar conta de algumas perspectivas oriundas do setor administrativo, logo quando o trabalho de campo apontava para outros rumos. As comunidades de Caraíbas (município de Canhoba), Ladeiras (município de Japoatã) e Forte (município de Cumbe) apresentavam uma linguagem e práticas fortemente conectadas a certas imagens do domínio do sobrenatural e do mitológico. $\mathrm{Na}$ qualidade de 'ecos do passado', esta linguagem apresentava um elemento subversivo que parecia ter resistido ao tempo. Além disso, os 'encantados' apresentavam-se como 'porta-vozes' acerca das noções de justo e de injusto orientadas pelo grupo (Salaini, 2012).

\footnotetext{
${ }^{18}$ A equipe foi composta por Cristian Jobi Salaini (antropólogo), Mariana Balen Fernandes (antropóloga), Aderval da Costa (antropólogo) e Vinícius P. de Oliveira (historiador).
} 
O 'clima' de interlocução entre membros da equipe, aquilo que constituía um campo de debatedores diretamente envolvido no processo demarcatório, para a construção de um relatório se dá, muitas vezes, sob essas percepções mais ou menos veladas acerca da 'objetividade' dos dados do relatório -narrativas, por si só, comprovariam algo? A operação administrativa precisa efetuar um recorte da vida quilombola que seja tangivel aos processos de classificação de controle. Por outro lado, o saber antropológico, através de sua característica eminentemente teórico-empírica, acaba por promover uma defasagem entre a complexidade das realidades concretas e aquelas que seriam possiveis pelas categorias, a priori, definidoras. Os processos diferenciados de produção de diálogo e interação dos grupos sociais com o 'aparato do reconhecimento' nos privilegiam o acesso a um processo criativo, sempre em curso, e não a comunidades como à espera de um tipo de devir histórico das categorias vindas 'de fora'. Nesse sentido, a tradução dos aspectos identitários dos grupos não devem se resumir a um tipo de 'registro historiográfico' (Chagas, 2005), pois ao nivel das 'outras sensibilidades' a experiência negra é múltipla, multifacetada e por vezes se utiliza de um registro histórico mitológico, e essa alteridade parece non sense aos operadores estatais.

As narrativas fantásticas, ao longo do trabalho de campo, quando colocadas ao curso do exame preciso, também levam à reconstituição de contextos mais amplos das atuações históricas constituídas pelos grupos. Os fragmentos, pequenos pedaços mitológicos, os 'restos' da casa grande onde os 'fantasmas' ainda habitam essas narrativas e, acabam por revelar, em seus interstícios, remetem a dados estruturais que permitem vislumbrar uma 'história de longa duração'.

Os antigos senhores, os antigos engenhos, os nomes dos antigos escravos fazem-se aparecer em meio ao percurso narrativo do fantástico. No relatório, o intento era o de não recair numa leitura que coloca o mitológico enquanto suporte para a chegada ao ponto final de uma 'realidade histórica'. Interessa-nos evidenciar o fato comunicativo que faz a vida mitológica colocar luz sobre a história e vice-versa: "Não lemos a memória como 'texto', mas como perspectiva da qual é possivel destextualizar os documentos escritos, tomando-os como 'falas' passíveis da análise antropológica" (Arruti, 2006, p.193). 
Em outras palavras, as readequações introduzidas na Instrução Normativa (n.57) reverberavam em novos desafios também para os peritos que percebiam o constante risco de uma 'inadequação' das narrativas das comunidades diante daquelas tidas e vistas como mais objetivas. Conduzir trabalhos etnográficos sob a tensão com lógicas estatais não é exatamente algo novo, mas nesse caso, a instrução normativa dava corpo a uma exigência de objetivação com maior poder de exclusão de formas de narrar e expressar marcos da memória das comunidades quilombolas.

\section{A negociação de peças objetivas: a objetificação na forma de mapas}

Do ponto de vista dos operadores administrativos, existe uma noção de território que, apesar de baseada na leitura antropológica através dos relatórios de identificação e delimitação, precisa fixar limites fisicos; o território apresenta-se em sua 'versão geométrica'. O mapa, confeccionado ao final do trabalho, traz uma adequação daquilo que se pode melhor traduzir do processo de construção etnográfica ${ }^{19}$.

A questão fundamental aqui diz respeito ao drama vivido, pelas comunidades e peritos, de ter de "encaixar" a história de uma comunidade dentro de um mapa. Ou de realizar um recorte, uma dobra do território (Ramos, 2009). E, de outra parte, ao valor científico conferido à ideia de perímetro e fechamento do território em uma unidade continua. $\mathrm{O}$ desafio, durante a perícia antropológica, consiste na procura de uma estabilização territorial mais adequada aos anseios políticos do grupo e também aos elementos produzidos pelo contato etnográfico: o mapa transforma-se num 'objeto' que, em diferentes sentidos, está aquém da complexidade etnográfica e, ao mesmo tempo, apresenta-se como um fato político, uma ferramenta técnica e política.

É exatamente por este motivo que o etnógrafo deve estar atento ao processo de negociação que ocorre dentro do espaço-tempo do relatório técnico. Não se trata apenas da produção de um 'banco de dados' de pontos de memória quilombola; o que está em jogo é a apreensão de

\footnotetext{
19 A este respeito ver Salaini (2012).
} 
um processo que inclui negociações e a assunção de riscos por parte dos grupos sociais.

Esta dobra do laudo/relatório é resultado e resultante de movimentos diversos. Seja porque os processos posteriores (pós-produção do relatório/laudo) de negociação com os demais agentes do Estado precisaram produzir uma demarcação exclusiva de certos elementos ou, seja porque, de forma bastante simples, o excedente simbólico da 'vida nativa' não é apreensível em um mapa, temos sempre a produção de um relato que simplifica em maior ou menor grau a vida nativa. Nesta tradução da vivência nativa na categoria de um 'povo' dotado de uma especificidade não há uma transmutação imediata de elementos; a tradução exige um processo que se demonstra sempre redutivo.

Ficamos diante de um processo que evidencia a dialética do reconhecimento. Em determinados casos, os grupos não procuram um tipo de 'reconhecimento direto'. Mas, ao entrarem no jogo dialético que perfaz o caminho do reconhecimento, aceitam a possibilidade de encontro com o mundo jurídico-administrativo enquanto um horizonte de possibilidades para tal expressão de visões de mundo que, do contrário, permaneceriam opacas aos peritos ou ao setor administrativo.

Houve em 2009 uma negociação entre INCRA e a comunidade quilombola dos Alpes sobre o formato final do território. Nesse campo de interlocução, inicialmente, o território quilombola, na forma apreendida pelo grupo, incorporaria a Estrada dos Alpes (que hoje acaba por "dividir" o espaço em dois). Claramente, na forma de percepção do espaço dirigida pelos quilombolas, tal estrada, construída de forma posterior à chegada de Dona Edwirges no morro, narrada como fato fundador da comunidade, faria parte do território. Em negociação com agentes responsáveis pelos Projetos Especiais do INCRA, a estrada ficou de fora da área a ser delimitada, a fim de evitar maiores problemas do ponto de vista fundiário e de possíveis e futuras indenizações aos moradores não quilombolas.

A negociação que se realizou, contudo, processa um recorte ainda maior que aquele já instaurado no relatório técnico. Cabe dizer que, mesmo durante o processo de confecção do relatório antropológico, os 
quilombolas mostravam a necessidade de se retirar do mapa determinados espaços a fim de, segundo eles, 'arranjar menos problemas'. Neste sentido, deve-se dizer que o território quilombola apresentado ao final do curso de um relatório antropológico é sempre resultado de uma estabilização. Uma estabilização que se dá pela tensão existente entre um "território do vivido" e um 'território do possível'.

O grupo, portanto, não está mais 'livre', e sua condição de pleiteante coloca novos riscos e o ônus da nova situação, não está de todo modo alheio a seus interlocutores. Neste sentido, não é dificil imaginar situações onde a 'escolha' da identidade traga desvantagens aos envolvidos, retirando do presente foco qualquer possibilidade de ativação instrumental da identidade. $O$ fato relevante seria a notabilidade sobre o fato de que os 'atores racionais' não estão livres das determinações sociais, tornando-se completamente 'soltos' em seu contexto social (Salaini, 2012).

Aos fins da presente análise, pretendemos reter a noção fundamental, em uma discussão de cunho etnográfico, sobre como os sujeitos realizam escolhas tendo como ponto de partida um horizonte ético e moral. Como pensar as possibilidades de evocação identitária, retomando a proposição de "que uma pessoa pode assumir, como essa pessoa pode manter a integridade do seu Eu? E, ainda, quais as condições de possibilidade de ação racional - isto é, reflexiva - no mundo moral?" (Cardoso de Oliveira, 2006, p. 62).

O 'mapa quilombola' apresentado no relatório técnico aos operadores administrativos que tem a função de produzir uma precisa delimitação de uma área física é profundamente inspirado em aspectos fundamentais da vida simbólica dos grupos estudados. Como vimos, através dos exemplos enfrentados na prática antropológica, não se trata de pensar o mapa como não representativo das aspirações territoriais quilombolas; ele é, contudo, incompleto fruto de diferentes processos de recorte que invadem o processo técnico e político de constituição do laudo/relatório. ${ }^{20}$ As técnicas de controle operadas no curso do diálogo

${ }_{20}$ Tal situação condiz com a expressão de uma experiência com o território e com o mundo social e não diretamente com uma forma de delimitação das fronteiras deste mundo, em um perímetro fechado e livre de interações com seus vizinhos. 
entre as categorias 'de cima' e as categorias quilombolas podem fazer transparecer uma unicidade onde, de fato, há uma fragmentação relativa. Apontar para os processos que constituem a complexidade dos enlaces territoriais, evocando os seus movimentos dinâmicos e repletos de niveis, revela uma importante possibilidade de não exotização e encaixe exagerado em categorias pré-arranjadas nas lógicas cartoriais hegemônicas.

\section{Considerações finais}

A partir de exemplos concretos, aqui apontamos para algumas tensões que percorrem as batalhas administrativas atuais e nos levam a indagar sobre as percepções de justiça compreendendo que elas se transferem à arena de negociações institucionais e científicas, em outras palavras, elas não se esgotam ou se traduzem plenamente nos instrumentos jurídico-administrativos.

Entendemos que os compromissos com arenas de promoção de reconhecimento extrapolam os sentidos dos dispositivos legais e se estendem para além do âmbito das políticas públicas e seus procedimentos administrativos. Assim, para que as comunidades quilombolas possam ultrapassar a experiência de estigmatização relacionada ao modo desvantajoso como historicamente se relacionaram com a lei, é importante visualizar quais lógicas, presentes na esfera administrativa e embasada em algumas das noções científicas de objetividade, ensejam a protelação de seu acesso a direitos. A essa arena aqui nomeamos como uma batalha dos papéis, evidenciando um campo de negociações sobre as formas de preencher de sentidos as rotinas administrativas.

Os relatórios técnicos são produzidos sob essa tensão de dar materialidade e, ao mesmo tempo, ampliar a receptividade de narrativas inusitadas e diversificadas, sob a pressão de exigências de objetificação. Contudo, se para os peritos isso é um desafio na elaboração de conhecimento, para as comunidades quilombolas converte-se em mais uma batalha de sua luta por reconhecimento, transposta para os papéis e escritórios de órgãos da administração local, aprendendo 
os novos caminhos institucionais e descobrindo lugares e sujeitos com quem podem estabelecer diálogos e serem então devidamente visibilizados. Evidenciamos que o procedimento demarcatório está permeado por jogos de interesses e pressões politicas que mobilizam recursos jurídicos administrativos e, em certo sentido, buscam 'esvaziar' a efetividade de práticas administrativas inovadoras, a partir da persistência em mobilizar argumentos tidos como objetivos e/ou universalistas.

O caminho das politicas reparatórias, no que tange a sua realização administrativa, revela um denso campo de interlocução que, na atualidade, vem exigindo das comunidades quilombolas novos aprendizados e uma maior capacidade de interlocução com o poder público.

\section{Referências}

Arruti, J. M. A. (2006). Mocambo: Antropologia e história do processo de formação quilombola. Bauru- São Paulo: Edusc.

Almeida, A. (2011). Quilombos e novas etnias. Manaus, UEA: Edições.

Barcellos, D., Chagas, M., Balen, M., Weimer, R., Muller, C.B., Moreira, P., Salaini, C. A. (2004). Comunidade negra de Morro Alto: Historicidade, identidade e territorialidade. Porto Alegre: Editora da UFRGS.

Cardoso De Oliveira, R. (2006). Caminhos da Identidade. Ensaios sobre etnicidade e multiculturalismo. São Paulo: Editora Unesp.

Carvalho, A. P. (2008). O espaço da diferença no Brasil: etnografia de políticas públicas de reconhecimento territorial e cultural negro no sul do país.

Carvalho, A. P. e Weimer, R. (2003). Família Silva: resistência negra no bairro Três Figueiras. Laudo antropológico e histórico de reconhecimento da comunidade remanescente de quilombo Família Silva. Agências financiadoras: Prefeitura Municipal de Porto Alegre e Fundação Cultural Palmares, Disponivel em: http:/ / www.ufrgs.br/naci/. 
Carvalho, J. J. (Orgs.). (1995). O Quilombo do Rio das Rãs. Histórias, Tradições, Lutas. Salvador: EDUFBRA.

Chagas, M. (2005). Estudos antropológicos nas comunidades remanescentes de quilombos: sinais que amplificam a luta por uma vida histórica, vida jurídica. Em Boaventura, I. (Org). Laudos periciais Antropológicos em Debate (p. 71-80). ABA/NUER, Florianópolis, Co-edição ABA/NUER.

Chagas, M. (2010). Antropologia em "movimento": lançando olhares sobre a auto-reflexividade etnográfica. En Chagas, M. y Muller, C. (Orgs). Dinâmicas da Cidadania. Abordagens etnográficas sobre a diversidade (p. 261-293). Porto Alegre: Editora da UFRGS.

Falk Moore, S. (1978). Law As Process: An Anthropological Approach. London, Boston: Routledge y K. Paul.

Fernandes, M. B. (2005). Ritual do maçambique: religiosidade e atualização da identidade étnica na comunidade negra do Morro Alto/RS [manuscrito].

Fonseca, C. (2004). Os Direitos da Criança: dialogando com o ECA. Em Fonseca, C. Terto, Jr., e Alves, C. F. (Orgs). Antropologia diversidade e direitos humanos: diálogos interdisciplinares (pp. 103-115). Porto Alegre: Editora da UFRGS.

Honneth, A. (2003). Luta por reconhecimento: a gramática moral dos conflitos sociais. São Paulo: Editora 34.

Jardim, D. F., Salaini, C. J., Muller, C., Dos Santos, S., Fochesatto, C. e Muller, M. (2007a). Comunidade remanescente Quilombo da Mormaça: História, Cotidiano e Territorialidade. (Relatório de pesquisa UFRGS- RTDI/INCRA-RS).

Jardim, D. F., Salaini, C. J., Muller, C., Dos Santos, S., Fochesatto, C. e Muller, M. (2007b). Casa de Avenida - Quilombo do Areal: legatários do Areal da Baronesa. (Relatório de pesquisa UFRGS - RTDI/INCRA - RS).

Jardim, D. F., Salaini, C. J., Muller, C., Dos Santos, S., Fochesatto, C. e Muller, M. (2007c). Chácara das Rosas: O ontem e o hoje de uma luta quilombola. Relatório Antropológico e Histórico de uma Comunidade Negra em Canoas/ RS.(Relatório de pesquisa UFRGS - RTDI/INCRA-RS). 
Jardim, D. F. (2013). Alteridades e (In) visibilidades: uma perspectiva antropológica sobre direitos humanos e dignidade. En Jardim, D.F. e Lopez, L. C. Politicas da Diversidade: (in) visibilidades, pluralidade e cidadania em uma perspectiva antropológica. (pp. 21-38). Porto Alegre: Editora da UFRGS.

Leite, I. B. (1995). Classificações étnicas e as terras de negros no Sul do Brasil. Em O`Dwyer, E.(Org). Boletim da ABA - terra de Quilombo (pp. 111-119). Rio de Janeiro: ABA: UFRJ.

Leite, I. (2002). O legado do testamento : a comunidade de Casca em perícia. Porto Alegre : Ed. da UFRGS.

Lima, S. (2011). Entre as lógicas do Estado e as comunidades quilombolas: reflexões sobre os percursos administrativos da regularização fundiária. Porto Alegre, UFRGS, Monografia de Conclusao de bacharelado em Ciencias Sociais, [manuscrito].

Lopes Da Silva, A. (1994). Há antropologia nos laudos antropológicos? Em Silva, O. A perícia antropológica em processos judiciais(pp. 60-66). Florianópolis: Editora da UFSC - ABA - Comissão Pró-ìndio.

López, L. (2013). Reflexões sobre o conceito de racismo institucional. En Jardim, D.F. y Lopez, L. C. Políticas da Diversidade: (in) visibilidades, pluralidade e cidadania em uma perspectiva antropológica. (pp. 73-92). Porto Alegre: Editora da UFRGS.

Müller, C. (2011). Direitos étnicos e territorialização: dimensãoes da territorialidade em uma comunidade negra. Porto Alegre : Ed. da UFRGS.

O’Dwyer, E. (2010). O papel social do antropólogo. A aplicação do fazer antropológico e do conhecimento disciplinar nos debates públicos do Brasil Contemporâneo. Rio: LACED, e-papers.

Oliveira Filho, J. (1999). Uma etnologia dos "indios misturados": situação colonial, territorialização e fluxos culturais. Rio: Contracapa. 
Oliveira Filho, J. (2004). Pluralizando tradições etnográficas: sobre um certo mal-estar na antropologia. Saúde dos Povos Indigenas: reflexões sobre a antropologia participativa (pp. 09-32). ABA: Contracapa.

Peirano, M. (1991). O antropólogo como cidadão. Em Uma antropologia no plural: três experiências contemporâneas (pp. 85-104). Brasilia: Editora da Universidade de Brasília.

Ramos, I. (2009). O lugar do parentesco na aliança entre um laudo antropológico e um território quilombola. Análise a partir do processo de regularização fundiária do Quilombo Cambará em Cachoeira do Sul/RS. Porto Alegre: PGDR, UFRGS.

Salaini, C. (2012). A "janela" do relatório técnico: variabilidade, criatividade e reconhecimento social em contextos de perícia antropológica. Porto Alegre, Brasil: Universidade Federal do Rio Grande do Sul.

Segato, R. L. (2006). Antropologia e Direitos Humanos: alteridade e ética no movimento de expansão dos direitos universais. Mana. Estudos de Antropologia Social, 2 (12), 207-236. Disponivel em: http:/ /www.scielo.br/pdf/mana/v12n1/ a08v12n1.pdf

\section{Cómo citar este artículo}

Salaini, C. J. (2015). Batalha dos papéis: Notas sobre as tensões entre procedimentos escritos e memória na regularização fundiária de terras de quilombos no Brasil. Universitas Humanística, 80, 189-212. http://dx.doi. org/10.11144/Javeriana.UH80.bdpn 